\title{
The Cluster-internal Ordering of Clitics in Kavalan (East Formosan, Austronesian)
}

\author{
DORIS CHING-JUNG YEN and LOREN BILLINGS \\ National Chi Nan University
}

Kavalan is an endangered language with fewer than one hundred speakers remaining (Chang 1997:21) and belongs to the Northern branch of East Formosan, itself a primary subgroup of Austronesian (Blust 1999:45-47). We investigate one part of Kavalan grammar: the relative order of adverbial and pronominal clitics. ${ }^{1}$

Of typological and theoretical import is the order within certain clusters of clitics. Transitive ordering has been defined, for a sequence of three morphemes-call them $X, Y$, and $Z$-as $X Y, Y Z, X Z$, and $X Y Z$ (Ryan 2010:785). By contrast, nontransitive ordering, involving the same three items, would be a situation where "(a) morpheme $\mathrm{X}$ must precede $\mathrm{Y}$, (b) $\mathrm{Y}$ must precede $\mathrm{Z}$, but (c) X must follow (or optionally follows) Z" (Ryan 2010:780). Whereas Kavalan does not attest the aforementioned kind of nontransitivity, this language does show another kind: $X Y, Y Z$, and $X Z$, but either $X Y Z$ or $X Z Y$. The transitive order $X Y Z$ is apparently in free variation with the nontransitive order $X Z Y$.

We organize this study as follows. Section 1 begins by introducing several adverbial clitics and one paradigm of clitic pronouns. Next, section 2 shows how various sequences of clitics are ordered, with particular attention devoted to the intricate internal ordering of an ABS-case pronoun relative to two adverbial clitics. $^{2}$ Section 3 then proposes an Optimality-theoretic analysis of this cluster-internal ordering, proposing a constraint against certain clitic sequences.

\footnotetext{
1 For various assistance along the way, we thank our main informants: Abas (Pan Tian-li), Anay (Chen Hsia-mei), Ipay (Chen Gao Yi-bai), Ukit (Pan Jin-ying), and Upa (Pan Chang-e). We also gratefully acknowledge the following colleagues' comments and other assistance: Celeste Chia-Yen Lee, Russell Lee-Goldman, Amy Pei-jung Lee, Wen-sheng Li, Ribix (Huang Shuo-wei), Justin Spence, and Sarah Thomason. Any mistakes that remain are entirely our own responsibility. We use these abbreviations: ABS absolutive, EXCL exclusive, FUT future, IMP imperative, INCL inclusive, NEG negation, OBL oblique, PCA phase-change aspect, PL plural, RS realis, RTA restriction of temporal alternatives, SG singular, TAM tense-aspect-modality, TR transitive, and 1/2/3 first/second/third person. In the literature, our labels ABS, OBL, RS, and TR are often called, respectively, nominative, accusative, Actor voice/focus, and Patient/Locative voice/focus. In the
} 


\section{Doris Ching-jung Yen and Loren Billings}

\section{Establishing the Inventory Clitics with Phrasal Positioning}

Two types of clausal clitics are attested in Kavalan: adverbial and pronominal. This section exemplifies these types and demonstrates that each is a clitic.

We begin by introducing a closed set of nonpronominal, adverbial clitics: (i) FUT $/=\mathrm{pa} /$, (ii) IMP $/=\mathrm{ka} /$, (iii) PCA $/=\mathrm{ti} /$, (iv) HEDGE $/=\mathrm{ma} /$, and (v) RTA /=pama/. Each is listed in (1) through (5), where the clitic follows the initial verb in the (b) example but must precede the verb in its negated (a) counterpart. This promiscuity of attachment is a crucial test of clitichood (Anderson 2005:31). In (2a) /assi/ is the allomorph of NEG /mai/ used only immediately before IMP /=ka/.

a. mai =pa uzan llan zau

NEG =FUT rain sky this

'It will not rain.' (cf. *mai uzan=pa llan zau)

b. uzan=pa llan zau

'It will rain.'

(Li and Tsuchida 2006:33, 219)

(2) a. assi =ka qan tu $\beta$ aut

NEG =IMP eat OBL fish

'Don't eat fish!'

(cf. * ${ }^{*}$ assi/mai $\}$ qan=ka tu $\beta$ aut)

b. qan=ka tu $\beta$ aut

'Eat fish!'

(Li and Tsuchida 2006:115, 259)

(3)

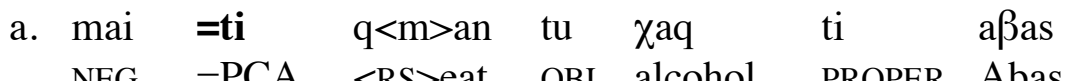

NEG =PCA $<$ RS $>$ eat OBL alcohol PROPER Abas

'Abas does not drink alcohol anymore.' (cf. *mai $\mathrm{q}<\mathrm{m}>\mathrm{an}=\mathrm{ti}$...)

b. $q<m>a n=t i$ tu $\chi$ aq ti aßas

'Abas has drunk alcohol.'

(all based on Yeh 2005:73)

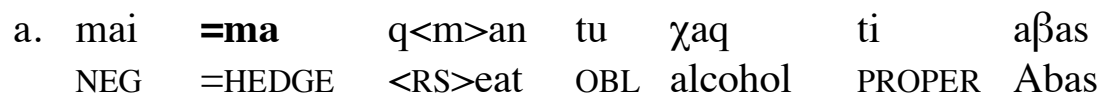

'Abas does not drink alcohol much.' (cf. *mai $\mathrm{q}<\mathrm{m}>\mathrm{an}=\mathbf{m a}$ tu $\chi \mathrm{aq} . .$. )

b. $\mathrm{q}<\mathrm{m}>$ an $=$ ma tu $\chi$ aq ti aßas

'Abas drinks alcohol a little.'

(all based on Yeh 2005:75)

examples below, other works' glosses are translated (with phonemic transcription following the IPA) without commenting on each change. We've added interlinear glosses to any examples from $\mathrm{Li}$ and Tsuchida (2006:63-530) as well. Our analysis of Kavalan actancy is now ergative (as in, e.g., Liao 2002), with /(-)m-/ analyzed as a marker of RS mood rather than voice. As such: each of (10b), (15), and (17) is TR, with an ABS-case Undergoer (but, due to IMP mood, the Actor is inaudible in each); in the remaining examples the ABS case encodes the clause's only core argument-but of these, (3) through (6), (8d), (10c), and (13), are furthermore antipassives (namely, with a peripheral-argument, OBL-case Undergoer). However, this paper's analysis does not hinge on these ergative assumptions. Examples without a source indicated come from our data. 
(5) a. mai =pama $q<m>a n$ tu $\chi$ aq ti aßas NEG =RTA <RS >eat OBL alcohol PROPER Abas

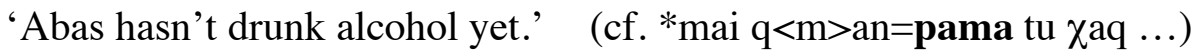

b. $\mathrm{q}<\mathrm{m}>$ an=pama tu $\chi$ aq ti aßas

'Abas still drinks alcohol.'

(all from Yeh 2005:75)

We follow the spirit of Tsuchida (1993:94-95) - and in turn Lin (1996:25), Lee (1997:59-66), and Yeh (2005:61) - in glossing the verbal affix in (3a-b), (4a-b), (5a-b), (6a-b), (8b, d), (10c,e), and (13) as RS mood. In addition to this infix, a prefixal allomorph is selected by other verbs, as in (8c), (10d), and (16a-b) below. The co-occurrence of this RS affix with various TAM clitics has not been fully sorted out in the literature (but see Huang and Sung 2008:162-164; Lee 1997:107-113, 127-129; Yeh 2005:55-60). In some of our examples removing or inserting this affix is possible; we haven't checked all the combinations.

In terms of their semantics, FUT / =pa/ and IMP/=ka/ in (1) and (2) clearly encode tense and modality, respectively. Lin proposes that $/=\mathrm{ti} /$ expresses a turning point between adjacent events or states, marking "phase-change aspect" (1996:48, $78-83$ ), as in (3). Moreover, /=ma/ in (4) marks hedged epistemic modality and /=pama/ in (5) is translated into English as 'still', or - in polar contexts - 'yet' (Yeh 2005:56). We gloss /=pama/ as "restriction of [... temporal] alternatives" (Krifka 2000:404). As such, all five adverbial clitics fall within the TAM semantic domain. ${ }^{3}$ Comparing the (a) and (b) pairs in (1) through (5) - in which the same TAM clitic is used in each - the (a) examples are NEG-initial, whereas their affirmative (b) counterparts begin with the verb. This comparison shows clearly that the TAM markers are positioned as clitics: hosted by the clause-initial free element, not always belonging to the same lexical category (Anderson 2005:31).

Having demonstrated that FUT /=pa/, IMP / =ka/, PCA /=ti/, HEDGE /=ma/, and RTA /=pama/ constitute a natural morphosyntactic and semantic class, we call this the TAM clitics. We know of no other TAM markers positioned in this way. ${ }^{4}$

As in (1) through (5), ABS-case bound pronouns display clitic positioning:
a. mai =iku $\mathrm{q}<\mathrm{m}>$ an tu $\chi \mathrm{aq}$ NEG =ABS.1SG $<$ RS $>$ eat OBL alcohol
'I don't drink alcohol.'
b. $q<m>a n=i k u$ tu $\chi a q$
'I \{drank/drink\} alcohol.'

(Yeh 2005:74)

\footnotetext{
3 Etymologically, /=pama/ may be the fusion of FUT /=pa/ in (1) and HEDGE /=ma/ in (4), but its RTA meaning does not follow from a combination of FUT plus HEDGE. For this reason, synchronically this disyllabic form must be stored lexically apart from both /=pa/ and /=ma/.

There are also clause-final TAM markers: for example, hortative /=ka/, distinct from IMP /=ka/ in allowing Actors that are (i) overt and (ii) [+me, +you] (Lee 1997:82; Li and Tsuchida 2006:115). Other TAM markers - e.g., the RS morpheme above on this page-are affixes.
} 
Doris Ching-jung Yen and Loren Billings

Unlike TAM clitics, which must precede the verb in a negated clause, ABS-case clitic pronouns have another option: being hosted by the verb regardless of whether another free form (e.g., NEG) precedes the verb (Yeh 2005:31-34, contra Chang 1997:111-113/1999). Thus, /mai q<m >an=iku tu $\chi$ aq/ is possible (Yeh 2005:73), in apparently free variation with (6a). In addition, a second pronominal paradigm exists: ergative (in a TR clause, used to encode the Actor). That bound paradigm is invariably positioned right after the verb (contra two examples in Huang et al. 1999:195). Numerous studies (including Chang 1997:117-120/1999, 2000:92-93; Lee 1997:41; Yeh 2005:32) analyze this ergative paradigm as affixes and markers of agreement (rather than pronouns and clitics, resp.). In this study, we consider only clitic clusters that follow NEG and precede the verb: unambiguously clitic positioning. (After an initial verb, an ergative-case pronominal must precede any of the clitics discussed in this paper. In any event, we have verified that the co-occurrence of an ergative pronominal does not affect the order of two TAM clitics and an ABS-case clitic pronoun relative to each other - the main issue below in this paper. Space limitations do not allow us to list such data here.)

Table (7) lists the full paradigm of pronominal clitics relevant to this study.

(7) Inventory of Clitic Pronouns with Clausal Positioning

\begin{tabular}{|c||c|c|c|c|c|}
\hline Glosses & 1SG & EXCL1PL & INCL1PL & 2SG & 2PL \\
\hline $\begin{array}{c}\text { Formal } \\
\text { Features }\end{array}$ & $+\mathrm{me},-\mathrm{you}$, & $+\mathrm{me},-\mathrm{you}$, & $+\mathrm{me},+\mathrm{you}$, & $-\mathrm{me},+\mathrm{you}$, & $-\mathrm{me},+\mathrm{you}$, \\
$+\mathrm{pl}$ & $+\mathrm{pl}$ & $+\mathrm{pl}$ & $-\mathrm{pl}$ & $+\mathrm{pl}$ \\
\hline Forms & $=\mathrm{iku}$ & $=\mathrm{imi}$ & $=\mathrm{ita}$ & $=\mathrm{isu}$ & $=\mathrm{imu}$ \\
\hline
\end{tabular}

Clitic ABS.3 pronouns are inaudible (as in many nearby Austronesian languages).

To summarize section 1, there are only ten key morphemes relevant to this study: five TAM clitics and a five-member paradigm of ABS clitic pronouns. Each of these follows the clause's first free element. In all our data, this clause-initial free element is either NEG (realized as either/mai/ or /assi/) or the verb.

\section{$2 \quad$ The Ordering Facts}

We now discuss how two or more clitics are ordered relative to each other within a cluster. Recall that there are two kinds of ordering: transitive and nontransitive.

If TAM clitics co-occur, their ordering is shown in (8a-d).
NEG $=$ FUT $=$ PCA sleep
'Abas won't sleep tonight.'
b. assi =ka =ti $\mathrm{q}<\mathrm{m}>\mathrm{an}$
a. mai $=\mathbf{p a}=\mathbf{t}$
qainəp
ti aßas anuqaxaßi
PROPER Abas tonight
NEG $=$ IMP $=$ PCA $<$ RS $>$ eat
'Don't keep \{eating/drinking\}!'
(cf. *mai=ti=pa qainəp ti aßas ...)

$$
\text { (cf. } *\{\text { assi } / \text { mai }\}=\text { ti }=\mathbf{k a} \mathrm{q}<\mathrm{m}>\mathrm{an} \text { ) }
$$


c. mai =ti =ma m-issi ti a NEG $=$ PCA $=$ HEDGE RS-fat PROPER Abas

'Abas is no longer very fat.'

(cf. *mai=ma=ti m-issi ti aßas; both based on Yeh 2005:60)

d. assi =ka =pama $\mathrm{q}<\mathrm{m}>$ an tu $\chi$ aq

NEG $=$ IMP $=$ RTA $<$ RS $>$ eat OBL alcohol

'Don't keep drinking alcohol!' (cf. * assi/mai $\}=$ pama=ka $\mathrm{q}<\mathrm{m}>\mathrm{an} . .$. )

Only these four orders are acceptable. (We have neither found in the literature nor successfully elicited clusters with more than two TAM clitics.) These ordering facts and co-occurrence restrictions are summarized in the following table.

(9) Co-occurring TAM Clitics

\begin{tabular}{|c|c|c|c|c|c|}
\hline & $\mathrm{FUT}=\mathrm{pa}$ & $\mathrm{IMP}=\mathrm{ka}$ & $\mathrm{PCA}=\mathrm{ti}$ & HEDGE $=\mathrm{ma}$ & RTA =pama \\
\hline $\begin{array}{l}\text { FUT } \\
=\mathrm{pa}\end{array}$ & & $\begin{array}{l}\mathrm{A} \\
*=\mathrm{pa}=\mathrm{ka}\end{array}$ & $\begin{array}{l}B \\
=p a=t i\end{array}$ & $\begin{array}{l}\mathrm{C} \\
*=\mathrm{pa}=\mathrm{ma}\end{array}$ & $\begin{array}{l}\mathrm{D} \\
*=\mathrm{pa}=\text { pama }\end{array}$ \\
\hline $\begin{array}{l}\text { IMP } \\
=\mathrm{ka}\end{array}$ & $\begin{array}{l}\mathrm{E} \\
*=\mathrm{ka}=\mathrm{pa}\end{array}$ & & $\begin{array}{l}\mathrm{F} \\
=\mathrm{ka}=\mathrm{ti}\end{array}$ & $\begin{array}{l}\mathrm{G} \\
*=\mathrm{ka}=\mathrm{ma}\end{array}$ & $\begin{array}{l}\mathrm{H} \\
=\mathbf{k a}=\mathbf{p a m a}\end{array}$ \\
\hline $\begin{array}{l}\text { PCA } \\
=\mathrm{ti}\end{array}$ & $\begin{array}{l}\mathrm{I} \\
*=\mathrm{ti}=\mathrm{pa}\end{array}$ & $\begin{array}{l}\mathrm{J} \\
*=\mathrm{ti}=\mathrm{ka}\end{array}$ & & $\begin{array}{l}\mathrm{K} \\
=\mathrm{ti}=\mathbf{m a}\end{array}$ & $\begin{array}{l}\mathrm{L} \\
*=\mathrm{ti}=\text { pama }\end{array}$ \\
\hline $\begin{array}{l}\text { HEDGE } \\
=\mathrm{ma}\end{array}$ & $\begin{array}{l}\mathrm{M} \\
*=\mathrm{ma}=\mathrm{pa}\end{array}$ & $\begin{array}{l}\mathrm{N} \\
*=\mathrm{ma}=\mathrm{ka}\end{array}$ & $\begin{array}{l}\mathrm{O} \\
*=\mathrm{ma}=\mathrm{ti}\end{array}$ & & $\begin{array}{l}\mathrm{P} \\
*=\mathrm{ma}=\text { pama }\end{array}$ \\
\hline $\begin{aligned} & \text { RTA } \\
&= \text { pama } \\
&\end{aligned}$ & $\begin{array}{l}\mathrm{Q} \\
*=\text { pama }=\text { pa }\end{array}$ & $\begin{array}{l}\mathrm{R} \\
*=\text { pama }=\mathrm{ka}\end{array}$ & $\begin{array}{l}\mathrm{S} \\
*=\text { pama }=\mathrm{ti}\end{array}$ & $\begin{array}{l}\mathrm{T} \\
*=\text { pama }=\mathrm{ma}\end{array}$ & \\
\hline
\end{tabular}

As this table shows, we have also verified that (i) /=ti/ is semantically incompatible with /=pama/ (Yeh 2005:59), as in cells L and s; (ii) $* /=\mathrm{pa}=\mathrm{ma} /$, without resulting in the distinct RTA meaning of $/=\mathrm{pama} /$, in cell $\mathrm{C}$; (iii) $* /=\mathrm{ma}=\mathrm{pa} /$, in cell M; (iv) the incompatibility of either $/=\mathrm{ma} /$ or $/=\mathrm{pa} /$ with $/=$ pama/ itself, in cells $\mathrm{D}, \mathrm{P}, \mathrm{Q}$, and $\mathrm{T}$; and (v) the unacceptability of $/=\mathrm{ka} /$ co-occurring with either $/=\mathrm{pa} /$ or $/=\mathrm{ma} /$, in cells A, E, G, and N. Furthermore, cells I, J, O, and R list the unacceptable opposite cluster-internal orders of the four attested sequences in (8a-d).

Arithmetically, 120 combinations of the five TAM clitics are possible. Because of various co-occurrence restrictions, however, only four overt clusters are found, each with only two members. These four orders, as the following discussion will show, hold true regardless of whether a clitic pronoun is also present.

Next, (10a-e) show how a single TAM clitic is ordered relative to an ABS pronoun. In each example the TAM clitic must precede the ABS pronoun. This is true even if the verb hosts both these clitics, not exemplified here. (Recall as well from the preceding page that, even in a negated clause, an ABS clitic pronoun can be hosted by the verb. Such ordering is irrelevant to the current discussion.) 
Doris Ching-jung Yen and Loren Billings

(10) a. mai =pa =isu qainəp $\chi a \beta i$ zau

NEG $=$ FUT $=$ ABS.2SG sleep night this

'Won't you sleep tonight?' (cf. *mai=isu=pa qainəp $\chi a \beta i$ zau)

b. assi =ka =imi pukun-an

NEG =IMP =ABS.EXCL1PL beat-TR

'Don't beat us!' (cf. $*\{$ assi/mai $\}=\mathbf{i m i}=\mathbf{k a}$ pukun-an)

c. mai =ti =iku $\mathrm{q}<\mathrm{m}>\mathrm{an}$ tu $\chi \mathrm{aq}$

$\mathrm{NEG} \quad=\mathrm{PCA}=\mathrm{ABS} .1 \mathrm{SG} \quad<\mathrm{RS}>$ eat $\mathrm{OBL}$ alcohol

'I don't drink alcohol any longer.' (cf. *mai=iku=ti q<m>an tu $\chi a q)$

d. mai =ma =iku m-issi

NEG =HEDGE =ABS.1SG RS-fat

'I am not very fat.' (based on Yeh 2005:59; cf. *mai=iku=ma m-issi)

e. mai =pama =iku $\mathrm{q}<\mathrm{m}>$ an

$\mathrm{NEG}=\mathrm{RTA}=\mathrm{ABS} .1 \mathrm{sG} \quad<\mathrm{RS}>$ eat

'I haven't eaten yet.'

(Li and Tsuchida 2006:221; cf. *mai=iku=pama $\mathrm{q}<\mathrm{m}>$ an)

Thus, in a two-clitic cluster, the ordering follows a fixed pattern: any two TAM clitics (themselves in a rigid order) or any single TAM preceding an ABS pronoun.

If an ABS pronoun and two TAM clitics co-occur, rather than (transitive) $=\mathrm{TAM}=\mathrm{TAM}=\mathrm{ABS}$ the order can also be (nontransitive) $=\mathrm{TAM}=\mathrm{ABS}=\mathrm{TAM}$. Data of this kind from the literature are shown in (11) through (13) and (16a).

(11) qainəp =pa =ti =iku

sleep $=$ FUT $=$ PCA $=$ ABS. $1 \mathrm{SG}$

'I'm going to bed.'

(Lin 1996:80, translation modified)

(12) a. qatiw =pa =iku =ti $\chi \mathbf{i}-\beta a u t$

go $=$ FUT $=$ ABS.1SG $=$ PCA catch-fish

'I am going fishing.' (Chang 2000:56, our translation)

b. $\ldots$ qan =pa =ita =ti

eat $=$ FUT $=$ ABS.INCL1PL $=$ PCA

'... we're about to eat.' (Li and Tsuchida 2006:34, 259, our translation)

c. qan $=$ pa $=$ imu $=$ ti

eat $=$ FUT $=$ ABS. $2 \mathrm{PL}=\mathrm{PCA}$

'Are you about to eat?' (Li and Tsuchida 2006:219, our translation)

(13) mai =ti =ma =iku $\mathrm{q}<\mathrm{m}>$ nut timaizipna

NEG $=$ PCA $=$ HEDGE $=$ ABS.1SG $<$ RS $>$ angry OBL.3SG

'I am no longer that mad at $\{$ her/him $\}$.'

(Li and Tsuchida 2006:151, translation modified) 
Lin lists (11) along with */qainəp=ti=pa=iku/ to show that FUT /=pa/ must precede PCA / =ti/ but does not discuss the order of $/=\mathrm{iku} /$ relative to both TAM clitics. The various other sources list (12a-c), (13), and (16a) without pointing out the clitic ordering at all. None of these is discussed with regard to the order of the ABS pronoun relative to the TAM clitics. The only additional published tokens not repeated here-all with the same type as in (12b) above (namely, with the interpolating cluster $/=\mathrm{pa}=\mathrm{ita}=\mathrm{ti} /)-$ are listed in $\mathrm{Li}$ and Tsuchida $(2006: 86,370,375)$.

In (14) through (17), our informants accepted both =TAM=TAM=ABS in the (a) examples and $=\mathrm{TAM}=\mathrm{ABS}=\mathrm{TAM}$ in their $(\mathrm{b})$ counterparts.

(14) a. mai =pa =ti =iku qainəp anuqaхa $\beta \mathbf{i}$

NEG =FUT $=$ PCA $=$ ABS.1SG sleep tonight

b. mai=pa=iku=ti qainəp anuqa $\alpha a \beta i$

'I will not sleep tonight.'

(15) a. assi $=\mathbf{k a}=\mathbf{a} \quad=\mathbf{i m i}$ pukun-an NEG $=$ IMP $=$ PCA $=$ ABS.EXCL1PL beat-TR

b. assi=ka=imi=ti pukun-an

'Don't beat us!'

(16) a. mai =ti =ma =iku m-ri rizaq NEG $=$ PCA $=$ HEDGE $=$ ABS.1SG RS-INTENSITY $\sim$ happy

(Li and Tsuchida 2006:151; reduplication inserted, as in Lee 2009:138)

b. mai=ti=iku=ma m-ri rizaq

'I am no longer very happy.'

(our translation)

(17) a. assi =ka =pama =imi pukun-an

NEG $=$ IMP $=$ RTA =ABS.EXCL1PL beat-TR

b. assi=ka=imi=pama pukun-an

'Don't keep beating us!'

The variation between these (a) and (b) examples is not geographic as far as we can determine. All speakers from whom we elicited these data so far happen to be female. Nor have we detected variation based on the speakers' ages. If this language is in flux, we have no sense of this type of change's directionality: Amis, the only other extant member of the East Formosan primary subgroup of Austronesian (Blust 1999:45-47), attests no bound pronouns (Huang et al. 1999:167).

We assume that the (a) and (b) patterns represent separate grammars competing in the speaker's mind. In the (a) grammar the clitics are ordered transitively, with any TAM clitics preceding an ABS clitic pronoun. In the nontransitive, interpolating (b) grammar, an ABS clitic pronoun must follow at least one TAM clitic (if one is present) but must appear between co-occurring TAM clitics. 


\section{Doris Ching-jung Yen and Loren Billings}

To summarize, we have shown that the co-occurrence of two TAM markers and an ABS pronoun can result in two orders: (i) transitive $=\mathrm{TAM}=\mathrm{TAM}=\mathrm{ABS}$ and (ii) nontransitive $=\mathrm{TAM}=\mathrm{ABS}=\mathrm{TAM}$ (also referred to here as interpolating).

\section{$3 \quad$ Analysis}

We now formalize the clitic-ordering facts using Optimality Theory (as surveyed, e.g., in McCarthy 2002). In this framework, grammars are differentiated by the ranking of a presumably common set of violable output constraints. The two grammars alluded to in the preceding section share four identically ranked constraints but differ only in the ranking of one other constraint relative to those four.

To begin, several constraints require various TAM clitics to be cluster-initial:

(18) a. FUT-1ST: If there's a FUT clitic, then it immediately follows its host.

b. IMP-1ST: If there's an IMP clitic, then it immediately follows its host.

c. PCA-1sT: If there's a PCA clitic, then it immediately follows its host.

d. TAM-1ST: If there's a TAM clitic, then it immediately follows its host.

Violation of these constraints is measured in terms of the number of morphemes separating this clitic from its host. In addition, because TAM-1ST can pertain to more than one clitic, multiple violations of it are also possible (for instance, if two TAM clitics are separated from the host by a clitic pronoun). Such gradient violation is evident in the three-clitic tableaux below in (25) and (26).

Before introducing our fifth constraint, we know the rankings in (19), from three (partially intersecting) markedness subhierarchies (also called stringency relations in McCarthy 2002:20, 44): violation of any of FUT-1ST, IMP-1ST, or PCA-1st entailing violation of TAM-1ST but the converse not necessarily true. ${ }^{5}$

\section{$\{$ FUT-1ST, IMP-1ST, PCA-1ST $\} »$ TAM-1ST}

The first type of cluster we address is with only TAM clitics. Recall from (8a-b) above that FUT $/=\mathrm{pa} /$ and IMP $/=\mathrm{ka} /$ each precede PCA $/=\mathrm{ti} /$. In order to

\footnotetext{
5 The curly braces in (19) indicate that there is no ranking among FUT-1ST, IMP-1ST, and PCA-1ST relative to each other. However, each of these three constraints dominates TAM-1ST (where » is shorthand for 'dominates'). In each tableau below, the upper-left cell indicates the input: an unordered set of lexical representations. The constraint names are then arrayed along the remaining top-row cells. The various clitic orders - two each in (20), (21), and (23); six each in (25) and (26) - are listed as candidates (or competing outputs) in the remaining left-hand cells. The pointing-finger icon shows the optimal candidate. Each violation of a constraint is listed in the cell under the constraint name and to the right of the candidate. A $W$ or $L$ appears in a cell if the non-optimum candidate on that row violates a particular constraint more or less (resp.) than the optimum. A ranking is established in any row of cells with a single $W$ and one or more $L$ s, where the constraint above the $W$ dominates any constraints above any $L$ (McCarthy 2002:32-33; Prince 2002/2003). We address separately multiple- $W$ rows in connection with (26) below.
} 
force a violation of the PCA-1sT constraint, as tableaux (20) and (21) demonstrate, each of FUT-1ST and IMP-1ST must be ranked above PCA-1sT, respectively.

[See (8a) above for the full example.]

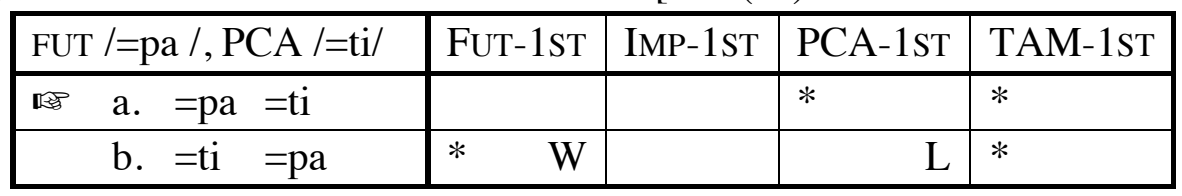

The non-optimum candidate in (20b) violates FUT-1ST (because FUT /=pa/ doesn't immediately follow its host), whereas the optimum in (20a) violates PCA-1sT (because PCA / $=\mathrm{ti} /$ isn't cluster-initial). Thus, tableau (20) demonstrates that FUT-1ST dominates PCA-1st, which accounts for the order of $/=\mathrm{pa} /$ before $/=\mathrm{ti} /$.

[See (8b) above for the full example.]

\begin{tabular}{|c|l|l|l|l|l|}
\hline $\mathrm{IMP} /=\mathrm{ka} /, \mathrm{PCA} /=\mathrm{ti} /$ & FUT-1ST & IMP-1ST & PCA-1ST & TAM-1ST \\
\hline a. $=\mathrm{ka}=\mathrm{ti}$ & & & & $*$ & $*$ \\
\hline b. $=\mathrm{ti}=\mathrm{ka}$ & & $*$ & $\mathrm{~W}$ & $\mathrm{~L}$ & $*$ \\
\hline
\end{tabular}

Similarly, tableau (21) demonstrates that IMP-1ST dominates PCA-1ST. The final ranking, common to both grammars, can thus be updated from (19) as follows.

\section{(22) $\{$ FUT-1ST, IMP-1ST $\} »$ PCA-1ST » TAM-1ST}

Incidentally, there is no need for constraints pertaining specifically to the HEDGE or RTA markers because (i) these never precede another TAM clitic, as table (9) above shows, and (ii) the generic TAM-1sT constraint is sufficient to assure that a TAM clitic precedes an ABS clitic pronoun in combinations of one of each kind of pronoun. Space limitations preclude listing tableaux corresponding to the remaining examples with two TAM clitics in section 2 above: (8c-d). These do not demonstrate any rankings because in each example the attested order fares (i) at least as well on every constraint as the opposite clitic order and (ii) better on at least one constraint. In such a situation, the optimum harmonically bounds the other candidate. For instance, in the tableau corresponding to $(8 \mathrm{c}), /=\mathrm{ti}=\mathrm{ma} /$ '=PCA=HEDGE' and */=ma=ti/ each (i) satisfy FUT-1ST, (ii) satisfy IMP-1ST, and (iii) violate TAM-1ST once (because in each order, one of the two TAM clitics is not cluster-initial). However, only $* /=m a=t i /$ violates PCA-1ST. Similarly, in all of the data above with one TAM clitic and a clitic pronoun, the TAM-initial order violates no constraints, in (10a-e). The opposite order violates at least TAM-1sT. Tableau (23) below illustrates this idea: (23a) harmonically bounds (23b). We don't list Ws or $L s$ in harmonically bounded candidates. Though (23) establishes no ranking, it shows that TAM-1ST is needed to eliminate ABS-initial clusters. 
Doris Ching-jung Yen and Loren Billings

[See (10e) above for the full example.]

\begin{tabular}{|c|l|l|l|l|}
\hline $\mathrm{RTA} /=$ pama /, ABS.1SG /=iku/ & FUT-1ST & IMP-1ST & PCA-1ST & TAM-1ST \\
\hline a. =pama =iku & & & & \\
\hline b. =iku =pama & & & & $*$ \\
\hline
\end{tabular}

The same single violation of TAM-1ST is found in the tableau corresponding to (10d), not shown here. The tableaux corresponding to (10a-c), likewise not listed here, would incur violations, respectively, in the opposite order's candidate under FUT-1ST, IMP-1ST, and PCA-1ST (as well, of course, as under TAM-1ST itself).

We now present tableaux where the two grammars differ: with three-clitic clusters. The transitive, =TAM=TAM=ABS clusters make up the (a) grammar, whereas the interpolating, $=\mathrm{TAM}=\mathrm{ABS}=\mathrm{TAM}$ orders comprise the (b) grammar. In the preceding tableaux the only attested form is the optimum and vice versa. For each three-clitic cluster in (14) through (17), there are now two attested orders. The (a) order is the optimum in the (a) grammar, whereas its (b) counterpart is the (b) grammar's optimum. Thus, though there are multiple attested orders in all the data from this point forward, there is still only one optimum per tableau.

The constraints in (18a-d), as ranked in (22), are fully able to account for the (a) examples in (14) through (17). That is, adding the ABS clitic pronoun to the tail end of the cluster incurs no additional violations of any of these constraints. Due to space limitations, we cannot show tableaux corresponding to these four orders with only the four constraints so far-but see (25) below using all five constraints. We leave it to the reader to verify that (22) can generate the (a) examples. Clearly, however, (18a-d) and (22) fail to do the same for the (b) grammar's examples.

Next, we add our fifth and final constraint to differentiate the two grammars. We propose that nontransitive ABS-interpolation in the (b) grammar is captured by a constraint against adjacent TAM clitics, reminiscent of the Obligatory Contour Principle, which states that consecutive, phonologically identical elements are prohibited (where contour here means consecutive tones with different pitches). This idea is first proposed in Leben (1973/1980), where underlying representations containing adjacent identical segments on the tonal tier are excluded, and has then spread within phonology to areas outside tonology proper. Furthermore, Kornfilt (1986:72) has observed that Turkish morphology "precludes immediate sequences of 'similar' morphemes. The crucial notion of 'similarity' is not one of phonological identity, but rather refers to the category and function of the morphemes involved." Namely, Kornfilt's constraint rules out consecutive sequences of morphosematically identical agreement morphemes in Turkish.

In Kavalan's (b) grammar an ABS pronoun can interrupt two TAM clitics. ${ }^{6}$ We attribute such positioning to the aforementioned prohibition on adjacent

6 It is unlikely that the relevant identical property is the number of syllables. Four of the TAM clitics - FUT $/=$ pa/, IMP $/=\mathrm{ka} /$, PCA $/=\mathrm{ti} /$, and HEDGE $/=\mathrm{ma} /-$ are monosyllabic (with only 
elements with some identical morphosemantic property: being a TAM clitic. To account for the nontransitive grammar, we propose our only remaining constraint:

(24) OCP-TAM: Adjacent tense-aspect-modality clitics are prohibited.

Unlike (18a-d), this is a categorical constraint; no more than one violation per cluster can occur. If the cluster consists only of TAM clitics, then either order of the clitics violates this constraint. Adding an OCP-TAM column would show one violation per candidate in tableaux (20) and (21) above, none in (23). This constraint differentiates between candidates only where there is also a clitic pronoun.

Clearly, OCP-TAM is needed to generate interpolation adequately. Before proceeding to our analysis of the (b) grammar, however, we show how OCP-TAM fits into the hierarchy in (22) of the distinct (a) grammar. (If a constraint is proposed, it is useful to show how this constraint interacts with the other constraints not just in grammars where this new constraint is needed. The typological predictions of introducing a constraint to the hierarchy can be quite instructive.) In tableau (25) we show how OCP-TAM, if added to the hierarchy in (22) above, would function in the transitive, non-interpolating (a) grammar.

[See (16a) above for the full example.]

\begin{tabular}{|c|c|c|c|c|c|c|c|}
\hline \multicolumn{4}{|c|}{ PCA /=ti/, HEDGE /=ma/, ABS.1SG /=iku/ } & \multirow[t]{2}{*}{ PCA-1ST } & \multicolumn{2}{|c|}{ TAM-1ST } & OCP-TAM \\
\hline 国 & a. $=\mathrm{ti}$ & $=\mathrm{ma}$ & $=\mathbf{i k u}$ & & * & & * \\
\hline & b. $=\mathrm{ti}$ & $=\mathbf{i k u}$ & $=\mathrm{ma}$ & & ** & W & L \\
\hline & c. $=\mathrm{ma}$ & $=\mathrm{ti}$ & $=\mathbf{i k u}$ & * & * & & * \\
\hline & d. $=$ ma & $=\mathbf{i k u}$ & $=\mathrm{ti}$ & ** & ** & & \\
\hline & e. $=\mathbf{i k u}$ & $=\mathrm{ti}$ & $=\mathrm{ma}$ & * & $* * *$ & & * \\
\hline & f. $=i k u$ & $=\mathrm{ma}$ & $=\mathrm{ti}$ & $* *$ & $* * *$ & & $*$ \\
\hline
\end{tabular}

The optimum (25a) harmonically bounds (25c), (25b) bounds (25d), and each of (25a-b) bounds each of (25e-f). Accordingly, (25[a b]) demonstrates that TAM-1ST » OCP-TAM. Building on the hierarchy in (22) above, the final ranking for the (a) grammar is \{FUT-1ST, IMP-1ST $\} »$ PCA-1ST » TAM-1ST » OCP-TAM.

Our last tableau demonstrates the position of OCP-TAM in the (b) grammar:

RTA /=pama/ being heavier). Moreover, all ABS clitics are disyllabic, at least in their citation forms; see table (7). However, in (14b) $/=$ pa=iku=ti/, (15b) $/=\mathrm{ka}=\mathbf{i m i}=\mathrm{ti} /$, and $(16 \mathrm{~b}) /=\mathrm{ti}=\mathbf{i k u = m a} /$ each of the three clitics is monosyllabic; each pronoun's initial /i/ does not project a sonority peak. These surface respectively as [paj.ku.ti], [kaj.mi.ti], and [ti.ku.ma]. In (14b) and (15b) this /i/ surfaces as a glide, [j], whereas in (16b) there is coalescence of /...i $=\mathrm{i} \ldots /$ into a single [i]. Furthermore, in (17b) /=ka=imi=pama/ the argument - about a monosyllabic clitic keeping disyllabic clitics apart-falls apart, because a monosyllabic pronoun separates TAM clitics with one and two syllables, respectively: [kaj.mi.pa.ma]. If anything, (17a), /=ka=pama=imi/ [ka.pa.maj.mi], with a disyllabic clitic between monosyllabic clitics, is an argument against having interpolation. 
Doris Ching-jung Yen and Loren Billings

[See (14b) above for the full example.]

\begin{tabular}{|c|c|c|c|c|c|c|c|}
\hline \multicolumn{4}{|c|}{$\mathrm{FUT} /=\mathrm{pa} /, \mathrm{PCA} /=\mathrm{ti} /, \mathrm{ABS} .1 \mathrm{sG} /=\mathrm{iku} /$} & OCP-TAM & FUT-1ST & PCA-1ST & TAM-1ST \\
\hline & a. $=$ pa & $=\mathrm{ti}$ & $=\mathrm{iku}$ & $\mathrm{W}$ & & $\mathrm{L}$ & $\mathrm{L}$ \\
\hline In: & b. $=\mathrm{pa}$ & $=$ iku & $=\mathrm{ti}$ & & & $* *$ & $* *$ \\
\hline & c. $=\mathrm{ti}$ & $=\mathrm{pa}$ & $=\mathbf{i k u}$ & $\mathrm{W}$ & W & $\mathrm{L}$ & $\mathrm{L}$ \\
\hline & d. $=\mathrm{ti}$ & $=\mathrm{iku}$ & $=\mathrm{pa}$ & & $* *$ & $\mathrm{~L}$ & $* *$ \\
\hline & e. $=\mathbf{i k u}$ & $=\mathrm{pa}$ & $=\mathrm{ti}$ & $*$ & $*$ & $* *$ & $* * *$ \\
\hline & f. $=\mathbf{i k u}$ & $=\mathrm{ti}$ & $=\mathrm{pa}$ & $*$ & $* *$ & $*$ & $* * *$ \\
\hline
\end{tabular}

Of primary importance here is that OCP-TAM $\gg$ PCA-1ST, TAM-1ST $\}$, as (26[b a]) demonstrates. ${ }^{7}$ Combined with hierarchy (22) above, common to both grammars, we see that in the (b) grammar OCP-TAM is undominated. See (27b).

This section has formalized the relative ordering of an ABS clitic pronoun and one or more TAM clitics using an Optimality-theoretic approach. The position of OCP-TAM in the constraint hierarchy differentiates the two grammars. Building on (22) above, the final rankings for the two Kavalan grammars are as follows.

a. The transitive grammar

FUT-1ST IMP-1ST

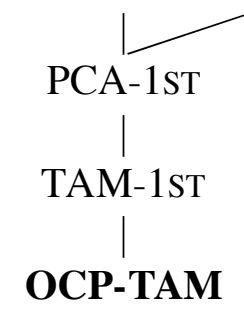

b. The ABS-interpolating grammar

OCP-TAM FUT-1ST IMP-1ST

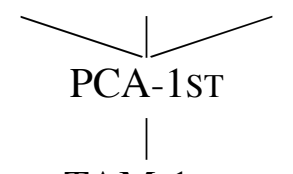

TAM-1sT

If TAM-1ST dominates OCP-TAM, as in (27a), then an ABS pronoun follows both TAM clitics in the cluster: fully transitive ordering. However, if OCP-TAM dominates at least some of the other constraints, as in (27b), then an ABS pronoun interrupts the TAM clitics: nontransitive, interpolating ordering. ${ }^{8}$ Two slightly

7 Each of (26a-c) harmonically bounds (26e), and each of (26a, c-d) bounds (26f). In addition, (26[b d] ) demonstrates that FUT-1ST » PCA-1ST, corroborating a known ranking, from tableau (20) above. Finally, (26[b c]) shows no new rankings (only that at least one of OCP-TAM and FUT-1ST dominates PCA-1ST and at least one of OCP-TAM and FUT-1ST dominates TAM-1ST). We also leave it to the reader to verify that (i) the tableau corresponding to (15b) also shows that OCP-TAM $\gg\{$ PCA-1ST, TAM-1ST $\}$ (among other, already established rankings) and (ii) tableaux corresponding to (16b) and (17b) each show only that OCP-TAM » TAM-1ST.

8 In Kavalan's (b) grammar it is impossible to rank OCP-TAM relative to either FUT-1ST or IMP-1ST (because at least one of the TAM clitics invariably precedes the ABS clitic pronoun and the FUT and IMP clitics never follow another TAM clitic). The rankings in (19) above, along with OCP-TAM, predict another grammar: \{FUT-1ST, IMP-1ST, PCA-1ST\} » OCP-TAM » TAM-1ST. Such a ranking - using Kavalan data - would predict interpolation only in (16b) and (17b). 
differing constraint rankings capture the distinctions in how clitics are ordered relative to each other. In each of the two-candidate clusters, OCP-TAM does no real work, and the two grammars generate the same clitic ordering. Our two-grammar approach also accounts for the variation within three-clitic clusters.

\section{Conclusion}

Kavalan constitutes an important addition to the typology-primarily in the Austronesian languages - of how clitics are positioned. In Central Philippine (Bloomfield 1917:181 [337], Kaufmann 1916:37), Squliq - and possibly Mayrinax C'uli' - Atayal (Liao 2005:53-57, 60), and Hebrew (Hetzron 1972:253-254) the order of two pronouns relative to each other is determined by their (increasing) prosodic weight. Moreover, adverbial clitics in Central Philippine languages follow monosyllabic pronouns but precede heavier ones (Billings and Kaufman 2004:27; Schachter 1973). Such clitic pronouns thus usually sandwich any adverbial clitics. In Kavalan it is the adverbial (i.e., TAM) clitics that can sandwich a clitic pronoun. Once again we see exceptional ordering-known in the literature as special syntax (Zwicky 1977:4-5, 14; Anderson 2005:75-82) - within the clitic cluster, not found among morphosyntactically free elements.

\section{References}

Anderson, Stephen R. 2005. Aspects of the Theory of Clitics (Oxford Studies in Theoretical Linguistics 11). New York: Oxford University Press.

Billings, Loren, and Daniel Kaufman. 2004. Towards a Typology of Austronesian Pronominal Clisis. In P. Law, ed., Proceedings of AFLA 11 [the Eleventh Meeting of the Austronesian Formal Linguistics Association] (ZAS Papers in Linguistics 43), 15-29. Berlin: Zentrum für Allgemeine Sprachwissenschaft.

Bloomfield, Leonard. 1917. Tagalog Texts with Grammatical Analysis. University of Illinois Studies in Language and Literature 3(2-4):1-408 [157-564].

Blust, Robert. 1999. Subgrouping, Circularity and Extinction: Some Issues in Austronesian Comparative Linguistics. In E. Zeitoun and P. J. Li, eds., Selected Papers from the Eighth International Conference on Austronesian Linguistics (Symposium Series of the Institute of Linguistics 1), 31-94. Taipei: Institute of Linguistics (Preparatory Office), Academia Sinica.

Chang, Henry Y. [Yung-li Chang]. 1997. Voice, Case, and Agreement in Seediq and Kavalan. Ph.D. thesis, National Tsing Hua University, Hsinchu, Taiwan. Encapsulated 1999, Glot International 4(6):10. 
Doris Ching-jung Yen and Loren Billings

Chang, Henry Y. [張永利]．2000．噶瑪蘭語參考語法 [Kavalan Reference Grammar (in Chinese)] (台灣南島語言 [Formosan Languages] 12). Taipei: Yuan-liu.

Hetzron, Robert. 1972. Phonology in Syntax. Journal of Linguistics 8(2):251-265.

Huang, Lillian M., Elizabeth Zeitoun, Marie M. Yeh, Anna H. Chang, and Joy J. Wu. 1999. A Typological Overview of Pronominal Systems of Some Formosan Languages. In H. Wang, F. Tsao, and C. Lien, eds., Selected Papers from the Fifth International Conference on Chinese Linguistics, 1.165-198. Taipei: Crane.

Huang, Shuping, and Li-May Sung. 2008. The Undergoer Focus $m a$ - in Kavalan. Oceanic Linguistics 47(1):159-184.

Kaufmann, John. 1916. Principles of Visayan Grammar. Oroquieta, Manila: Catholic Trade School.

Kornfilt, Jaklin. 1986. The Stuttering Prohibition and Morpheme Deletion in Turkish. In A. Aksu Koç and E. Erguvanl1-Taylan, eds., Proceedings of the Second International Conference on Turkish Linguistics (Boğaziçi University Publications 400), 59-83. İstanbul: Boğaziçi University.

Krifka, Manfred. 2000. Alternatives for Aspectual Particles: Semantics of still and already. In L. J. Conathan, J. Good, D. Kavitskaya, A. B. Wulf, and A. C. L. $\mathrm{Yu}$, eds., Proceedings of the Twenty-sixth Annual Meeting of the Berkeley Linguistics Society: General Session and Parasession on Aspect, 401-412. Berkeley: Berkeley Linguistics Society.

Leben, William. 1973. Suprasegmental Phonology. Ph.D. thesis, Massachusetts Institute of Technology, Cambridge, MA. Published 1980, New York: Garland.

Lee, Amy Pei-jung. 1997. The Case-marking and Focus Systems in Kavalan. M.A. thesis, National Tsing Hua University, Hsinchu, Taiwan.

Lee, Amy Pei-jung. 2009. Kavalan Reduplication. Oceanic Linguistics 48(1):130-147.

Li, Paul Jen-kuei, and Shigeru Tsuchida. 2006. Kavalan Dictionary (Language and Linguistics Monograph Series A-19). Taipei: Institute of Linguistics, Academia Sinica. 
Liao, Hsiu-chuan. 2002. The Interpretation of $t u$ and Kavalan Ergativity. Oceanic Linguistics 41(1):140-158.

Liao, Hsiu-chuan. 2005. Another Look at the Order of Clitic Pronouns in Wulai Atayal. Concentric: Studies in Linguistics 31(1):47-63.

Lin, Ju-en. 1996. Tense and Aspect in Kavalan. M.A. thesis, National Tsing Hua University, Hsinchu, Taiwan.

McCarthy, John J. 2002. A Thematic Guide to Optimality Theory. Cambridge: Cambridge University Press.

Prince, Alan. 2002. Arguing Optimality. Rutgers Optimality Archive 562 $<$ roa.rutgers.edu>. Published 2003, in A. Coetzee, A. Carpenter, and P. de Lacy, eds., Papers in Optimality Theory II (University of Massachusetts Occasional Papers 26), 269-304. Amherst, MA: Graduate Linguistic Student Association.

Ryan, Kevin M. 2010. Variable Affix Order: Grammar and Learning. Language 86(4):758-791.

Schachter, Paul. 1973. Constraints on Clitic Order in Tagalog. In A. B. Gonzalez, ed., Parangal kay Cecilio Lopez (Special Monograph Issue 4), 214-231. Manila: Linguistic Society of the Philippines.

Tsuchida, Shigeru [土田滋]. 1993. カバラン語 [The Kavalan Language (in Japanese)]. In T. Kamei, R. Kōno, and E. Chino, eds., The Sanseido Encyclopaedia of Linguistics, 5.89-99. Tokyo: Sanseido.

Yeh, Yu-Ting. 2005. Negation in Kavalan: A Syntactic Study. M.A. thesis, National Taiwan University, Taipei.

Zwicky, Arnold M. 1977. On Clitics. Bloomington: Indiana University Linguistics Club.

Department of Foreign Languages and Literature

National Chi Nan University

1 University Road

Puli, Nantou Hisen 545 Taiwan

doris.c.yen@gmail.com,sgnillib@gmail.com 